IONIC ORGANIC MECHANISMS 
Titles in the Dimensions of Science Series

Energy and Cells C. Gayford

Genes and Chromosomes J. R. Lloyd

Practical Ecology D. Slingsby and C. Cook

Ionic Organic Mechanisms C. Went 
DIMENSIONS OF SCIENCE

Series Editor: Professor Jeff Thompson

\section{IONIC ORGANIC MECHANISMS}

\section{Charles Went}

Coventry Lanchester Polytechnic

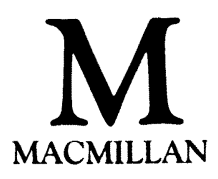


All rights reserved. No reproduction, copy or transmission of this publication may be made without written permission.

No paragraph of this publication may be reproduced, copied or transmitted save with written permission or in accordance with the provisions of the Copyright Act 1956 (as amended).

Any person who does any unauthorised act in relation to this publication may be liable to criminal prosecution and civil claims for damages.

First published 1986

Published by

MACMILLAN EDUCATION LTD

Houndmills, Basingstoke, Hampshire RG21 2XS

and London

Companies and representatives

throughout the world

British Library Cataloguing in Publication Data

Went, Charles

Ionic organic mechanisms.-(Dimensions of science)

1. Chemical reaction, Conditions and laws of

I. Title II. Series

541.3'9 QD502

ISBN 978-0-333-39160-0

ISBN 978-1-349-07964-3 (eBook)

DOI $10.1007 / 978-1-349-07964-3$ 


\section{Contents}

Acknowledgements vii

Introduction viii

1 Structure and Physical Properties of Organic Molecules 1 Structural terminology. Polar molecules. The inductive effect. Physical properties of polar molecules

2 The Concept of Resonance

Mesomeric effect. MO description of conjugated molecules.

Limiting forms. Induced polarisation. Manifestation of resonance. Determination of resonance energy. Bond lengths.

Electric dipole moments. Spectral data

3 Classification of Reactions and Reagents

Annotated equations. Classification of reactions and reagents.

Mechanistic equations. Use of partial structures

4 Organic Acids and Bases

General concepts. Measurement of acidity and basicity.

Conjugate acids and bases. Acidity of carboxylic acids.

Acidity of phenols. Acidity of alcohols. Basicity of amines

5 Nucleophilic Substitution

Reactions of haloalkanes. Unimolecular and bimolecular mechanisms. Energy profiles, transition states and intermediates. Stereochemistry. The Hammond Postulate.

Unsaturated halocompounds. Reactions of alcohols, phenols, ethers and amines

6 Elimination

Haloalkanes. Unimolecular and bimolecular mechanisms.

Substitution versus elimination. Reactions of alcohols and amines 
7 Nucleophilic Reactions of Carbonyl Compounds

Addition and addition with elimination. Acidic hydrogen.

Tautomerism. Condensation reactions

8 Nucleophilic Reactions of Carboxylic Acids and their

Derivatives

Reactions of carboxylic acids. Reactions of acid chlorides.

Reactions of acid anhydrides. Reactions of esters. Reactions of acid amides

9 Electrophilic Addition Reactions of Alkenes and Alkynes Addition reactions of alkenes. Oxidation of alkenes. Hydrogenation of alkenes. Reactivity of buta-1,3-diene. Reactions of alkynes

10 Aromatic Electrophilic Substitution

220

Mechanism of nitration, sulphonation, halogenation, and

Friedel-Crafts reaction. Electronic effects of substituents.

Steric effects

Outline Solutions to Exercises

Brief Bibliography: some more-advanced textbooks

Index 


\section{Acknowledgements}

I would like to thank the Senior Science Editor, Ms Mary Hoddinott, and the Series Editor, Professor Jeff Thompson, for their advice and encouragement in the preparation of this manuscript. 


\section{Introduction}

\section{WHY STUDY ORGANIC REACTION MECHANISMS?}

There are many possible answers to this question! A teacher might reply that it is an interesting way of introducing what is called the scientific method'. He or she might also point to the pleasure which can result from satisfying the natural curiosity that chemists have about the way in which reactions occur.

Of more appeal to the student, perhaps, is that a good understanding of mechanisms provides a means of correlating and rationalising a large volume of otherwise apparently unrelated reactions. It is not intended that a mechanistic study of organic chemistry should replace the traditional approach, but in an integrated course even a simple treatment of mechanisms can help to give 'rhyme and reason' to many of the reactions studied.

It can also be argued, of course, that there are good economic reasons for studying mechanisms. The more that is known about the way in which a reaction occurs, the more successful a chemist is likely to be in designing a new synthesis or improving an existing process.

\section{ABOUT THIS BOOK}

Since this is a book just about mechanisms, it will be assumed that you have already made some progress in your study of organic chemistry, and are conversant with basic ideas of structure and stereochemistry, etc. Even so, the first four chapters are devoted to a revision of some of the concepts and terminology considered essential to the study of ionic mechanisms.

The order of subsequent chapters in which particular mechanisms (such as nucleophilic substitution or alkene addition) are discussed, may differ from that of the course which you are taking. If this is the case, you are still advised to read chapter 5 before embarking on other topics, because it is in the discussion of nucleophilic reactions that many of the ideas assumed viii 
to be familiar in later chapters are first introduced and explained. Throughout the text there are a number of exercises designed to help you assess your own understanding and progress. It is hoped that you will attempt at least some of these, and outline solutions are given at the end of the book. 